20

\title{
Learning That Matters: Discovery of Meaning and Development of Wisdom in Undergraduate Education
}

\author{
Thomas Mengel \\ University of New Brunswick
}

This paper makes the case for a shift of undergraduate education towards the development of meaningful life skills that are of value to the graduates as well as to the communities they live in. First, relevant connections between student learning, meaning, and wisdom will be made. Second, the article will explore how undergraduate education can more holistically and comprehensively support students in learning meaningfully and in developing elements of wisdom. In particular, the paper will suggest principles that allow the meaningful integration of learning outcomes, experiential learning opportunities, reflection, and assessment.

\section{Introduction}

Supportive learning environments and student Oengagement have come to the forefront of postsecondary education, particularly within the field of the scholarship of teaching and learning. However, university and college programs and structures still reflect the traditional disciplinary focus on knowledge development and transfer. Meaning - realizing something of creative, experiential, or attitudinal value (Frankl, 1985), and wisdom - the "capacity to realize what is of value in life for oneself and others" (Maxwell, 2008, p. 2), only recently have been rediscovered as potential ends of university education and as objects of their own rights in research and practice of higher education (Barnett \& Maxwell, 2008; Ferrari \& Potworowski, 2008; Kronman, 2007).
Based on the author's recent research (Mengel, 2007, 2008; Mengel, Cowan-Sahadath, \& Follert, 2009), this paper makes the case for a shift of undergraduate education towards the development of meaningful life skills that are of value to the graduates as well as to the communities they live in. First, relevant connections between student learning, meaning, and wisdom will be made. Second, the article will explore how undergraduate education can more holistically and comprehensively support students in learning meaningfully and in developing elements of wisdom. In particular, the paper will suggest principles that allow the meaningful integration of learning outcomes, experiential learning opportunities, reflection, and assessment. 


\section{Student Learning}

According to recent publications on the scholarship of teaching and learning, student learning needs to be constructive, cumulative, self-regulated, goal oriented, situated, collaborative, transformative, integrative, interactive, challenging, experiential, and meaningful (Gonyea \& Kuh, 2009; Huber \& Hutchings, 2005; Kuh, 2003; Mentkowski, 2000; NSSE, 2008). In particular, student learning should be focused on acquiring abilities that are a complex combination of motivation, disposition, attitudes, values, strategies, behaviours, self perception, knowledge of concepts, and knowledge of procedures (Mentkowksi, 2000). As a consequence, student learning requires teaching that feeds the various "intelligences" that address these components - cognitive, emotional, as well as spiritual intelligence - and that taps into knowledge within the respective various dimensions: expertise, management knowledge, as well as leadership knowledge and wisdom (Mengel, 2007). To do so, our efforts in regard to facilitating student learning obviously have to improve on helping students to discover meaning and to make meaningful connections as well as on developing wisdom.

\section{Meaning and Meaningful Learning}

In his seminal work Man's Search for Meaning, Viktor Frankl (1985) identified the search for meaning as the primary motivation for human beings. He suggested that we discover meaning in what we do by realizing creative values (e.g., creating something at work or in our learning environment), in what we experience by realizing experiential values (e.g., experiencing meaningful relationships in our personal and professional lives), and in what we believe and think by realizing attitudinal values (e.g., developing new and healthy attitudes when suffering professional setbacks or personal crises). Furthermore, he proposes that we discover meaning by answering the questions "why?" and "what for?" based on our personality and on the situational context we find ourselves in; hence, our personal situation needs to guide our discovery. Finally, this discovery process as well as professional practice require the development of the underlying abilities in the areas of spiritual intelligence in general and the development of wisdom in particular (Mengel, 2007).

\section{Wisdom and Wisdom Development}

Various wisdom traditions and definitions appear to gravitate towards two foci: wisdom as "knowledge" about how to live and about how the world works. Most concepts highlight the importance of balance and of a meaningful relationship with one's environment; many agree on the significance of living according to human nature while they may differ in terms of the detailed interpretation of this concept. This clearly requires development and practice of abilities around knowing oneself and knowing others through continuous training and "askesis." In some religious traditions concepts of wisdom do include an otherworldly or divine focus. Some highlight the importance of withdrawal and meditation as a means of participating in divine wisdom (Curnow, 2008).

The scientific approach of modernity resulted in a shift from looking for meaning to researching facts and thus put concepts of wisdom onto the back seat of scholarly endeavours. However, wisdom appears to experience a post-modern revival within and across various disciplines as indicated through various recent definitions of wisdom (Baltes \& Staudinger, 2000; Maxwell, 2008; Peterson \& Park, 2008; Stange \& Kunzmann, 2008; Sternberg, Jarvin, \& Reznitskaya, 2008). On a high level, the "Berlin wisdom model" (Baltes \& Staudinger, 2000) defines wisdom as "exceptional insight into the human condition and meaning of life" (Stange \& Kunzmann, 2008, p. 24), and in much more detail, suggests various basic criteria around expert knowledge and wisdom specific meta criteria. In their "balance theory of wisdom," Sternberg et al. (2008) describe wisdom as the "use of one's intelligence, creativity, and knowledge as mediated by values toward the achievement of a common good 
through a balance among (a) intrapersonal, (b) interpersonal, and (c) extrapersonal interests, over the (a) short and (b) long terms to achieve a balance among (a) adaptation to existing environments, (b) shaping of existing environments, and (c) selection of new environments" (p. 38). Peterson and Park (2008) in their approach of "positive psychology" identify wisdom to be the "ability to judge correctly in matters relating to life and conduct and/or understanding of what is true, meaningful or lasting" (p. 59). Finally, the British philosopher Maxwell (2008) urges political leaders and academic institutions to shift from knowledge to "wisdom inquiry" and defines wisdom as the "capacity to realize what is of value in life for oneself and others" (p. 2). He further suggests engaging in a cooperative process of applying and developing that capacity through learning how to well articulate problems of living and through proposing and assessing possible solutions (wise problem solving).

\section{Implications for Education: Principles of Meaningful Learning}

In order to achieve the required progression from knowledge to wisdom, any growth of university graduates or professionals in terms of traditional disciplinary knowledge has to be matched by a respective development of interdisciplinary and practical wisdom. First and foremost we need to shift from a model of individual knowledge transfer and assessment to an approach that goes beyond valuing students' abilities to maximize their own attainments by also valuing students' abilities to maximize attainment of others and to contribute to solving problems of life; our teaching needs to reward demonstration of wisdom as much as it rewards demonstration of academic knowledge. Furthermore, teaching for wisdom needs to help students learn how to balance competing interests and goals in the process of problem solving and to encourage them to form, critique, and integrate their own and others' values in their thinking and decision-making. Finally, students need to learn to think dialectically and dialogically and to search for and try to reach the common good. This can effectively only be achieved by an integrated curriculum and by considering yet challenging individual learning styles and personal preferences.

In particular, learning that matters, that contributes to solving problems of life, and has both individual as well as communal significance, needs to be designed around the following principles:

1. What is being learned has to be meaningful to both students and to the communities that the learners are part of. An ability based set of learning outcomes provides students and their communities with a transparent framework that allows them to make sense and discover meaning (Mentkowksi, 2000; Zundel et al., 2006). Within this outcome-based learning environment students need to be "doing" (creative values) and "experiencing" (experiential values) something meaningful as well as developing meaningful "attitudes" (attitudinal values) towards something within the context of both self and others and in particular in regard to the relationship of self and others.

Therefore, the learning context needs to be set up to include elements and challenges from the students' and their communities' current life situation. It also has to be linked to the context of their programs' learning outcomes. Finally, the learning environment has to actively consider the different personal learning styles and preferences.

In addition, the process of learning has to be set up to contribute to building and developing communities, to collaboratively solve problems of importance to communities, and to engage in the public discourse about significant issues.

2. Learning outcomes serve as a framework for student assessment and feedback. This framework will allow integrating assessment on a course as well as on a program level. It will also include the assessment of and feedback on personal growth as well as on the competency to contribute to the development of communities.

3. Teaching and learning needs to include elements that address both the individual and social aspects of learning and that are well balanced and spread around the Kolb Learning Cycle (1984). A balanced offering of group work, individual 
reflections, logical analyses, and active experimentations or fieldwork may serve this purpose.

Furthermore, these elements need to appeal to different personalities. This may be achieved through a mix of competitive tasks, cooperative assignments, and individual assignments on social, scientific, technological, and business topics. Finally, the elements need to be designed to allow for, to integrate, and to evaluate the discovery of creative, experiential, and attitudinal values. The learning environment needs to encourage students to create important results and relevant solutions, to experience meaningful relationships, and to develop healthy attitudes, particularly in the context of challenges, conflicts, and crises.

4. Meaningful assignments will assess student learning based on respective learning outcomes including both individual as well as social dimensions. In particular, they will consider various learning styles and personalities as well as individual and community settings. Finally, these assignments will speak to creative, experiential, and attitudinal values both within an individual as well as a community context.

5. Meaningful feedback will address student performance consistently based on respective outcome criteria. It also will consider the student's learning style and personality by explicitly acknowledging strengths and addressing opportunities for growth. Finally, it will address instances (as demonstrated by the student within the assignment) and opportunities (yet to be developed) for the discovery and realization of values in regard to self, to others, and to the relationship between self and others.

\section{Summary}

Teaching must comprehensively address cognitive, emotional, and spiritual intelligence to allow for student learning that is meaningful and matters to both the learners involved as well as to the communities that these learners are part of. Meaningful learning is supported by learning environments that encour- age students to create something meaningful, to have valuable experiences with something or someone, and to acquire new and meaningful attitudes (Frankl, 1985). Wisdom development will help students grow their "capacity to realize what is of value in life for oneself and others" (Maxwell, 2008, p. 2).

Within this context, learning outcomes need to reflect both individual growth and its potential to contribute the learners' communities. Furthermore, these learning outcomes also should serve as the framework for continuous and consistent feedback and assessment. Finally, the learning environment in general as well as the learning activities and assessment opportunities in particular ought to be well balanced around the Kolb Learning Cycle (1984) and to address the different learning preferences and personalities of all learners. While this comprehensive approach to meaningful learning and wisdom development goes far beyond the simple transfer of knowledge, learning that matters may better contribute to solving problems significant to individuals and to their communities alike.

\section{References}

Baltes, P.B. \& Staudinger, U.M. (2000). Wisdom: A metaheuristic (pragmatic) to orchestrate mind and virtue toward excellence. American Psychologist, 55(1), 122-136.

Barnett, R. \& Maxwell, N. (Eds.). (2008). Wisdom in the university ( $1^{\text {st }}$ ed.). New York, NY: Routledge.

Curnow, T. (2008). Sophia's world: Episodes from the history of wisdom. In M. Ferrari \& G. Potworowski (Eds.), Teaching for wisdom: Cross-cultural perspectives on fostering wisdom (pp. 1-19). New York: Springer.

Ferrari, M. \& Potworowski, G. (Eds.). (2008). Teaching for wisdom: Cross-cultural perspectives on fostering wisdom. New York: Springer.

Frankl, V.E. (1985). Man's search for meaning. Boston, MA: Beacon Press, Pocket Books. 
Gonyea, R.M. \& Kuh, G.D. (Eds.). (2009). Using NSSE in institutional research [Special issue]. New Directions for Institutional Research, 141.

Huber, M.T. \& Hutchings, P. (2005). The advancement of learning: Building the teaching commons. San Francisco, CA: Jossey-Bass.

Kolb, D.A. (1984). Experiential learning: Experience as the source of learning and development. Englewood Cliffs, NJ: Prentice-Hall.

Kuh, G.D. (2003). What we're learning about student engagement from NSSE. Change, 35(2), 24-32.

Kronman, A.T. (2007). Education's end: Why our colleges and universities have given up on the meaning of life. New Haven: Yale University Press.

Maxwell, N. (2008). Wisdom in the university. In R. Barnett \& N. Maxwell (Eds.), Wisdom in the university (pp. 1-19). New York, NY: Routledge.

Mengel, T. (2007). Leadership development for complex environments: Helping create a meaningful future. fmi Journal - Financial Management Institute of Canada, 19(01), $13-15$.

Mengel, T. (2008). Motivation. In J. Gosling \& A. Marturano (Eds.), Key concepts in leadership studies (pp. 111-114). Routledge, UK: Milton Park, Oxfordshire.

Mengel, T., Cowan-Sahadath, K., \& Follert, F. (2009). The value of project management to organizations in Canada and Germany, or Do values add value? Five case studies. Journal of PM, 40(1), 28-41.

Mentkowski, M. (2000). Learning that lasts: Integrating learning, development, and performance in college and beyond. San Francisco, CA: JosseyBass.

National Survey of Student Engagement [NSSE].
(2008). Promoting engagement for all students: The imperative to look within: 2008 results. Retrieved from http://nsse.iub. edu/ NSSE\%5F2008\%5FResults/docs/withhold/ NSSE2008_Results_revised_11-14-2008.pdf

Peterson, C. \& Park, N. (2008). The cultivation of character strength. In M. Ferrari \& G. Potworowski (Eds.), Teaching for wisdom: Crosscultural perspectives on fostering wisdom (pp. 59-77). New York: Springer.

Stange, A. \& Kunzmann, U. (2008). Fostering wisdom: A psychological perspective. In M. Ferrari \& G. Potworowski (Eds.), Teaching for wisdom: Cross-cultural perspectives on fostering wisdom (pp. 23-26). New York: Springer.

Sternberg, R.J., Jarvin, L., \& Reznitskaya, A. (2008). Teaching for wisdom through history: Infusing wise thinking skills in the school curriculum. In M. Ferrari \& G. Potworowski (Eds.), Teaching for wisdom: Cross-cultural perspectives on fostering wisdom (pp. 37-57). New York: Springer.

Zundel, P., Bishop, M., Carr, M., Clarke, G., Colford, J. A., Mengel, T., et al. (2006). Outcomes-based learning at a whole program level. Alan Blizzard Award for collaborative projects that improve student learning. McGraw-Hill Ryerson.

\section{Biography}

Thomas Mengel is Associate Professor of Leadership Education, Renaissance College, at the University of New Brunswick. He has been involved in both teaching and learning in some form or other for more than 30 years. Thomas holds academic degrees in theology, adult education, history, and computer science. Before joining academia full-time in 2005, he held various project management and leadership positions and worked as a consultant in different European and North American organizations. His major focus is on project management and leadership education. 